\title{
O BENEFÍCIO PREVIDENCIÁRIO DE AUXÍLIO-RECLUSÃO: OS EFEITOS RESTRITIVOS DA LEI N. 13.846/2019
}

\section{THE SOCIAL SECURITY BENEFIT OF RECLUSION: THE EFFECTS RESTRICTIVE LAW No 13,846/ 2019}

\author{
Christiane Cruvinel Queiroz ${ }^{*}$
}

\begin{abstract}
RESUMO
O artigo discute os efeitos restritivos da Lei n. 13.846/2019, resultado da conversão da Medida Provisória n. 871/2019, na concessão do benefício previdenciário de auxílio-reclusão, devido aos dependentes do segurado preso e de baixa renda, num contexto de governo filiado ao aparato teórico neoliberal. Adotou-se como procedimento metodológico a revisão bibliográfica e pesquisa documental na temática do direito previdenciário e do benefício de auxílio-reclusão. Os resultados estão apresentados com a delimitação do tema na seara do regime geral de previdência social no Brasil; os requisitos legais para a concessão do auxílioreclusão e as alterações promovidas no instituto com a publicação da Medida Provisória n. 871/2019. Conclui-se que os novos critérios para a concessão do auxílio-reclusão, de caráter nitidamente restritivos, têm o condão de afetar, de maneira direta e imediata, a proteção social das inúmeras famílias de segurados presos e de baixa renda.
\end{abstract}

Palavras-chave: Previdência Social; Auxílio-Reclusão; Contrarreforma; Lei $13.846 / 2019$.

\begin{abstract}
The article discusses the restrictive effects in Law n. 13.846/2019, resulto $f$ conversion of Provisional Measure n. 871/2019 in the concession of social security benefit in reclusive help, to owen to dependentes of insured arrested and the low income, in a context of government afilliated with the neoliberal theoretical apparatus. The methodology is based on bibliographical assessment and documentary research on the theme of right social security and benefit of reclusive help. The results are presented with delimitation oh theme in the field of general social security scheme in Brazil; the legal requirements for the granting of reclusive help and the changes at institute wich the publication in Provisional Measure n. 871 , January 18, 2019. Concludes that new criteria for granting the seclusion aid, of strictly restrictive character, have the power to affect, directly and immediately, the social protection of numerous families of prisoners insured and of low income.
\end{abstract}

Key-Words: Social Security; Reclusive Help; Counterreform; Law 13.846/2019

\footnotetext{
* Graduada em Direito pela Universidade Metodista de Piracicaba (1997). Mestre em Ciências Sociais Aplicadas, na linha Estado, Direitos e Políticas Públicas pela Universidade Estadual de Ponta Grossa (2018). Servidora pública lotada no Ministério Publico Federal em Ponta Grossa/Pr. Tem experiência na área de Direito, com ênfase em Direitos Fundamentais, pesquisando principalmente nos seguintes temas: seguridade social, assistência social e políticas públicas sociais.
} 


\section{INTRODUÇÃO}

A seguridade social brasileira está concebida na Constituição Federal de 1988 como um sistema que integra um conjunto de ações de iniciativa dos poderes públicos e da sociedade com vistas a assegurar direitos sociais relativos à saúde, previdência social e assistência social. Traz a marca da proposta de universalização dos direitos sociais como forma de superação das desigualdades sociais numa sociedade de classes capitalista.

Como nos coloca Briguet, Victorino e Horvarth Junior (2007), o sistema de seguridade social impõe ao Estado a garantia de satisfação das necessidades sociais dos seus cidadãos, tanto no aspecto da prestação econômica quanto no fornecimento dos meios para que o indivíduo consiga superar as adversidades que possam surgir no seu dia a dia, quer pela via da assistência social, quer pela da saúde.

Um dos pilares da seguridade social edifica-se no sistema de previdência social, definido por Rocha (2009) como sendo um seguro social, de caráter compulsório e contributivo, cujo financiamento está a cargo dos trabalhadores e da sociedade e tem como objetivo ofertar aos segurados e dependentes os meios indispensáveis para a subsistência diante de situações que tornem inviável ou desaconselhável o sustento pelo trabalho.

De modo que a possibilidade de ampliação da proteção social previdenciária, assim como a capacidade redistributiva da riqueza social produzida, são alvos de constantes ataques e mudanças por setores conservadores que buscam refrear estes avanços sociais.

Assim é que o direito fundamental à previdência social, em tempos de governos filiados ao aparato teórico neoliberal ${ }^{1}$, tem sido alvo de reformas estruturais capazes de alterar o sistema público de proteção previdenciária, colocado por Costa (2017, p. 174) como o "[...] conflito entre a universalização e a ampliação da proteção previdenciária e as medidas de ajustes fiscais que alteram as regras para o acesso aos benefícios previdenciários".

\footnotetext{
${ }^{1}$ No ideário neoliberal prevalece a lógica de que a indesejável intervenção do Estado no enfrentamento das desigualdades sociais e econômicas, geradas no interior do sistema capitalista, resulta no aumento dos custos e diminuição dos lucros e no desestímulo dos trabalhadores que abandonariam o sistema produtivo em troca dos benefícios concedidos pelo Estado (FRIEDMAN, 1985).
}

É sabido que o Brasil, logo após a promulgação da Constituição Federal de 1988, tornou-se signatário das medidas neoliberais propagadas no Consenso de Washington e concretizadas por meio de medidas de ajuste fiscal, controle inflacionário e diminuição da presença do Estado na economia, as quais se traduziram numa ofensiva ao processo de construção dos direitos sociais recém-positivados na norma constitucional. Fagnani (1996, p. 86) denomina este movimento de "contrarreforma conservadora", levado a efeito por setores governamentais que pregavam a implementação de políticas sociais somente depois de alcançado o funcionamento adequado da economia e do crescimento do país.

Esta hegemonia neoliberal tem se prolongado desde então, com algumas nuances nos períodos dos governos de Lula e Dilma $(2003 / 2017)^{2}$. Na atualidade, temos vivenciado um "[...] aumento do conservadorismo e pela utilização de medidas neoliberais ortodoxas, que buscam atender os interesses do capital (inter)nacional e na mesma medida negligenciar as reais necessidades da maioria trabalhadora", como nos coloca Silva (2018, p. 156).

De modo que o artigo busca apreender, de forma crítica, as alterações promovidas no benefício previdenciário de auxílio-reclusão, ofertado no regime geral de Previdência Social - RGPS, num contexto de desmonte dos direitos sociais e, em especial, por se tratar de uma modalidade de benefício previdenciário que tem sido alvo de ataques negativos nos últimos tempos, tanto da sociedade civil quanto dos governantes e até mesmo de operadores do direito previdenciário.

Neste sentido, no período de campanha eleitoral, o presidente da república Jair Bolsonaro referiu-se ao benefício como "bolsa bandido"3. A Medida Provisória $n^{\circ} .871 / 2019$ (BRASIL, 2019), publicada nos primeiros dias do seu governo e posteriormente convertida na Lei 13.846/2019, teve o propósito de restringir a concessão do benefício de auxílio-reclusão,

\footnotetext{
${ }^{2}$ Para Kerstenetzky(2012) a experimentação inédita no país do modelo de interação entre políticas sociais e econômicas, com "políticas sociais economicamente orientadas" e "políticas econômicas socialmente orientadas" possibilitaram aliar medidas de ajuste fiscal em favor dos interesses do capital, em especial do financeiro, com um projeto de crescimento redistributivo.

${ }^{3}$ Matéria veiculada no portal Brasil de Fato. Disponível em: <https://www. brasildefato.com.br/2019/02/15/governo-busca-o-fim-do-auxilio-reclusao-entenda/>. Acesso em 2 de abr. de 2019.
} 
num evidente alinhamento 'político-ideológico', como nos adverte Neves (2011, p. 29).

Na pesquisa de Chies e Passos (2012), cujo campo empírico foi o ambiente virtual da internet, no ano de 2011, restou evidenciado que $38,7 \%$ das mensagens postadas em redes sociais sobre o instituto do auxílio-reclusão tinham cunho negativo, com categorias emergentes como a oposição entre trabalhador e delinquente; trabalho e ócio/crime; estímulo ao crime e tolerância zero.

No mesmo sentido, operadores do direito colocam-se contrários à previsão deste direito social, tal como Martins (1999, p. 285) que defende a extinção do benefício de auxílio-reclusão ao argumentar que: "“...] não é possível que a pessoa fique presa e ainda a sociedade como um todo tenha de pagar um benefício à família do preso, como se este estivesse falecido."

E não podemos deixar de observar que tramita a PEC n. 3/2019 (BRASIL, 2019) com a reunião de um pacote de medidas relacionadas à temática da segurança pública e, dentre elas, a proposição da extinção do benefício previdenciário de auxílio-reclusão.

De modo que diante do contexto de ataques frontais ao direito social do auxílio-reclusão, os quais ganham densidade diante da propagação de informações que reafirmam as representações sociais negativas sobre o instituto do auxílio-reclusão - como por exemplo, de que se trata de um benefício previdenciário pago diretamente ao cidadão preso -, é que se faz necessária a discussão deste instituto como forma de elucidação de um direito social de titularidade dos dependentes do segurado preso, assim como de enfrentamento às tentativas de desconstrução dos direitos sociais assegurados na Constituição Federal de 1988, em tempos de governos neoliberais.

\section{O auxílio-reclusão: requisitos legais}

O benefício previdenciário denominado auxílio-reclusão tem previsão assegurada no artigo 201, inciso IV, da Constituição Federal (BRASIL, 1988), com alteração da redação pela Emenda Constitucional n. 20 de 1998 (BRASIL, 1998).

Consiste na oferta de benefício pecuniário, substitutivo da renda do trabalhador e, portanto, nunca inferior ao valor do salário-mínimo, devido aos dependentes dos segurados de baixa renda, assim definida como a renda bruta mensal igual ou inferior a $\mathrm{R} \$$
360,00 (trezentos e sessenta reais), corrigida anualmente pelos mesmos índices aplicados aos benefícios do regime geral de previdência social, nos termos do artigo 13 da EC 20/1998 (BRASIL, 1998). Na atualidade, o teto financeiro para configuração do critério de baixa renda está fixado em R \$1.364,43, pela Portaria n. 9 do Ministério da Economia (BRASIL, Ministério da Economia, 2019).

Trata-se, pois, de um benefício intuitu familiae que sofreu restrição com o critério de seletividade da renda do segurado - imposto pela EC n. 20/1998 4 (BRASIL, 1998) -, duramente criticado à época, por operadores do direito, dentre eles Martinez (1999, p. 117) para quem: “A modificação do benefício, para pior, é incompreensível e discriminatória, convindo suscitar a impropriedade em face dos postulados fundamentais da Lei Maior".

Segundo nos coloca Russomano (1981) desde a criação dos Institutos de Aposentadoria e Pensões no Brasil, no início da década de 1930, já existiam previsões legais que buscavam amparar os dependentes do segurado detento ou preso. Inicialmente, o benefício foi previsto no ordenamento do Instituto de Aposentadoria e Pensões dos Marítimos IAPM; depois expandido para o extinto Instituto de Aposentadoria e Pensões dos Bancários - IAPB e, finalmente, generalizado para todos os segurados na Lei Orgânica da Previdência Social - LOPS (BRASIL, 1960).

Ainda segundo Russomano (1981, p. 214), o espírito da lei que ampara a família do segurado preso, reside na circunstância de que:

$\mathrm{O}$ criminoso, recolhido à prisão, por mais deprimente e dolorosa que seja a sua posição, fica sob a responsabilidade do Estado. Mas, seus familiares perdem o apoio econômico que o segurado lhes dava e, muitas vezes, como se fossem os verdadeiros culpados, sofrem a condenação injusta de gravíssimas dificuldades.

De modo que o instituto do auxílio-reclusão busca assegurar o direito fundamental previsto no artigo $5^{\circ}$., inciso XLV, da Constituição Federal (BRASIL, 1988), consistente na intranscendência da pena da

\footnotetext{
${ }^{4}$ É importante observar que, tal como nos coloca Faleiros (2010, p. 115), a reforma da previdência social com a promulgação da Emenda Constitucional n. 20/1998 foi o resultado da "[...] correlação de forças de predomínio de um bloco neoconservador [então] no poder, com discurso modernizante e políticas vinculadas ao Fundo Monetário Internacional".
} 
pessoa do acusado, em outras palavras, na garantia de que os efeitos da pena criminal não passarão da pessoa do preso em razão de ato ilícito por ele praticado.

A regulamentação dos benefícios previdenciários ocorreu com a publicação da Lei n. 8.213/1991 (BRASIL, 1991) que prevê a concessão do auxílio-reclusão, nos termos do artigo 80, cuja redação anterior à publicação da Medida Provisória n. 871/2019, convertida na Lei 13.846/2019, assim estabelecia:

Art. 80.0 auxílio-reclusão será devido, nas mesmas condições da pensão por morte, aos dependentes do segurado recolhido à prisão, que não receber remuneração da empresa nem estiver em gozo de auxílio-doença, de aposentadoria ou de abono de permanência em serviço.

Parágrafo único. O requerimento do auxílio-reclusão deverá ser instruído com certidão do efetivo recolhimento à prisão, sendo obrigatória, para a manutenção do benefício, a apresentação de declaração de permanência na condição de presidiário.

Na sequência, elencaremos os requisitos legais para a concessão do auxílio-reclusão aos dependentes do segurado preso e de baixa renda, sem as alterações promovidas inicialmente pela MP n. 871/2019 e ratificadas com a sua conversão na Lei 13.846/2019, as quais serão adiante abordadas de forma comparativa. Ainda trataremos dos posicionamentos adotados por nossos Tribunais, num critério ampliativo da cidadania social, sobre alguns dos requisitos legais para a concessão do auxílio-reclusão.

\subsection{Requisitos legais do auxílio-reclusão anteriores à Medida Provisória n. 781/2019 convertida na Lei $n$. 13.846/2019}

Para a compreensão dos efeitos restritivos dos novos critérios estabelecidos pela Medida Provisória n. 871/2019 e ratificados com a publicação da Lei 13.846/2019, no que diz respeito à concessão do benefício previdenciário de auxílio-reclusão, faz-se necessário, de antemão, abordamos os requisitos legais vigentes até então, alguns destes mantidos com a publicação da nova legislação.

O benefício previdenciário do auxílio-reclusão, como modalidade de seguro social e, portanto, de natureza contributiva, tem caráter temporário e natureza substitutiva da renda do segurado recluso.
Tem como fundamento assegurar proteção social, por meio do sustento financeiro, aos dependentes dos segurados obrigatórios ou facultativos ${ }^{5}$, enquanto permanecer encarcerado. Aqui reside a primeira polêmica deste benefício porque a despeito de ser devido aos dependentes do segurado recluso e não ao próprio preso é costumeiramente, no senso comum, apreendido como benefício pago em favor ou diretamente ao cidadão preso.

Para fazer jus ao recebimento do auxílio-reclusão, o segurado preso não pode receber remuneração da empresa ou encontrar-se em gozo de auxílio-doença ou aposentadoria.

Para a aferição do critério "baixa renda" deve-se levar em consideração o salário de contribuição do segurado na data do recolhimento à prisão. De modo que o último salário percebido pelo segurado recolhido à prisão, denominado de salário de contribuição para fins previdenciários, deve ser igual ou inferior a $\mathrm{R} \$$ $1.364,43$, a partir de janeiro de 2019. Como já dito, este teto financeiro é atualizado anualmente por portaria ministerial.

Nossos tribunais ${ }^{6}$ têm considerado que o critério econômico de baixa renda não é absoluto, podendo ser flexibilizado para a exclusão de parcelas não habituais no salário do segurado, como por exemplo o pagamento eventual de horas extras, na esteira dos entendimentos jurisprudenciais em relação ao critério econômico ${ }^{7}$ do benefício assistencial de prestação continuada, mais conhecido como BPC.

\footnotetext{
${ }^{5} \mathrm{O}$ rol dos segurados obrigatórios e facultativos da Previdência Social está previsto nos artigos 11 a 13 da Lei n. 8.213/1991.

${ }^{6}$ Neste sentido são os julgados: a) Superior Tribunal de Justiça. REsp. 1.479.564/SP, Relator: Ministro NAPOLEÃO NUNES MAIA FILHO, $1^{\text {a }}$ Turma, DJe 18.11.2014 Disponível em: <https://ww2.stj.jus.br/processo/pesqu isa/?termo $=1.479 .564 \&$ aplicacao $=$ processos.ea\&tipoPesquisa $=$ tipoPesquisaG enerica\&chkordem $=$ DESC\&chkMorto=MORTO $>$. Acesso em 6 abr. de 2019. b) Turma Nacional de Uniformização, Ação n. 0003705-39.2013.4.02.5050, Relatora: Carmem Elizangela Dias Moreira de Resende, Julgado em 22/03/2018. Disponível em:<https://eproctnu.cjf.jus.br/eproc/externo_controlador.php?acao $=$ inteiro_teor\&codigo_verificador $=900000022083 \mathrm{v} 5 \& \mathrm{co}$ digo_crc=996a4348>. Acesso em 01 abr. 2019.

${ }^{7}$ Nos termos do artigo 20 da Lei 8.742/1993 o critério econômico para aferição da hipossuficiência do idoso ou do portador de deficiência é de renda mensal per capita inferior a $1 / 4$ do salário-mínimo. O Supremo Tribunal Federal, no julgamento da ADIn n. 1.232/DF, declarou a inconstitucionalidade do critério legal de 1/4 do salário mínimo, por considerá-lo defasado para representar a situação de miserabilidade do cidadão requerente. Reconheceu-se a não exclusividade do critério de renda de $1 / 4$ do salário mínimo para fins de aferição da condição socioeconômica, podendo ser levado em consideração, no caso concreto, outros parâmetros para comprovação da condição de hipossuficiência econômica.
} 
A Turma Nacional de Uniformização proferiu julgados que afirmam ser necessário considerar a renda do segurado preso como parâmetro para a concessão do benefício e não a renda dos seus dependentes. Esta questão restou consolidada com o julgamento pelo Supremo Tribunal Federal do RE $587.365^{8}$ que ao firmar o entendimento de que era a renda do segurado preso que deveria ser utilizada como parâmetro para a concessão do benefício, também declarou a constitucionalidade do critério de seletividade estabelecido na Emenda Constitucional n. 20/1998.

De modo que ainda que a renda dos dependentes supere o teto do critério econômico para fins de apuração do conceito de baixa renda, o que deve ser levado em consideração é o valor da remuneração do segurado preso.

No caso do segurado encontrar-se desempregado na data de sua prisão, desde que mantida a sua qualidade de segurado, a autarquia previdenciária tem considerado como remuneração, para fins de aferição do critério de baixa renda, o último salário percebido pelo segurado recluso.

Sabe-se que a manutenção da qualidade de segurado, nos termos do artigo 15, inciso II, da Lei 8.213/91 (BRASIL, 1991), será mantida pelo período de até 12 (doze) meses após a cessação das contribuições pelo segurado que deixou de exercer atividade remunerada. E o $\S 2^{\circ}$, do mesmo artigo, estabelece que o referido prazo será acrescido de 12 (doze) meses quando o segurado estiver comprovadamente desempregado.

Apesar de a autarquia previdenciária retroceder para alcançar o último salário de contribuição do segurado que se encontrava desempregado no momento da prisão, nossos Tribunais ${ }^{9}$ têm entendido que a situação de desemprego gera ausência total de remuneração do segurado, devendo esta falta de renda ser considerada para fins de fixação do critério baixa renda, de forma

\footnotetext{
${ }^{8}$ RE 587.365, Supremo Tribunal Federal. Relatoria do Ministro Ricardo Lewandowski, julgado em 25 de março de 2009. Disponível em: < http:// redir.stf.jus.br/paginadorpub/paginador.jsp?docTP=AC\&docID=591563>. Acesso em 24 set. de 2019.

${ }^{9}$ Neste sentido, é o julgado do Tribunal Regional Federal da 1 ${ }^{\text {a }}$. Região na Apelação do MS 1999.36.00.008890-5/MT, de Relatoria do Desembargador Federal Luiz Gonzaga Barbosa Moreira, julgado em 14/05/2007. Acesso em: $<$ https://processual.trf1.jus.br/consultaProcessual/processo.php $>$. Acesso em 06 de abr. de 2019. Também o julgado do Superior Tribunal de Justiça no Resp 1480461/SP, de Relatoria do Ministro Herman Benjamin, 2a. Turma, DJe 10/10/2014. Disponível em: <https://ww2.stj.jus.br/processo/pesquisa/? termo $=1480461 \&$ aplicacao $=$ processos.$e a \&$ tipoPesquisa $=$ tipoPesquisaGeneri ca\&chkordem=DESC\&chkMorto=MORTO $>$. Acesso em 06 de abr. de 2019.
}

a não retroagir no tempo em busca do último salário de contribuição. Assim, ainda que os salários de contribuição anteriores do segurado preso tivessem sido superiores ao teto fixado em portaria ministerial, o critério de baixa renda restará configurado posto que o segurado não auferia renda no momento da sua prisão.

Para a concessão do auxílio-reclusão é preciso comprovar a qualidade de dependente do segurado, segundo o rol do artigo 16 da Lei n. 8.213/1991 (BRASIL, 1991). O valor do benefício é rateado igualmente entre todos os dependentes e a cota-parte recebida por um dependente é dividida igualmente entre os demais dependentes, quando um dos dependentes perde esta qualidade. E o benefício será extinto após a perda do direito do último dependente habilitado.

A data de início do benefício será fixada na data do efetivo recolhimento do segurado à prisão, se o benefício for requerido pelos dependentes do preso até trinta dias depois da data da prisão ou na data do requerimento, se posterior.

O benefício de auxílio-reclusão, dado o seu caráter temporário, era devido enquanto o segurado estiver recolhido à prisão sob regime fechado ou semiaberto. Também é devido aos dependentes do segurado maior de 16 anos e menor de 18 anos de idade, internado em estabelecimento educacional ou congênere, sob custódia do Juizado da Infância e Juventude.

Nos casos em que o segurado preso é transferido para o regime semiaberto harmonizado com monitoração eletrônica que lhe possibilita estudar, trabalhar e manter o convívio familiar, o posicionamento judicial tem sido de não considerar mais devido o pagamento do benefício de auxílio-reclusão aos dependentes haja vista a possibilidade do segurado de prover a família com o próprio trabalho.

Na hipótese de fuga do segurado preso, o benefício será suspenso e, se houver recaptura, será restabelecido a contar da data em que esta ocorrer, desde que esteja mantida a qualidade de segurado. Contudo, Coimbra (1997, p. 133) diverge desta previsão legal ao sustentar que o benefício é devido à família do segurado e, portanto, "[...] o fato de ter se evadido o segurado, de estar foragido, em nada altera os termos da questão, nem melhora a situação de seus dependentes, os titulares da prestação de que se cuida".

Por fim, vale mencionar que o exercício de atividade remunerada pelo segurado recluso na condição 
de cumprimento da pena, no regime fechado ou semiaberto, não acarreta a perda do direito ao auxílio-reclusão pelos seus dependentes, nos termos do artigo $2^{\circ}$. da Lei 10.666/2003 (BRASIL, 2003).

Para a concessão do benefício do auxílio-reclusão faz-se necessário o cumprimento de todos os requisitos acima elencados, o que vale dizer que o descumprimento de apenas um dos requisitos pode acarretar o indeferimento ou a cessação do benefício previdenciário.

Em linhas gerais, estes são os requisitos legais para a concessão do benefício previdenciário de auxílio-reclusão previstos na legislação que antecedeu a publicação da Medida Provisória n. 871/2019 e sua posterior conversão na Lei 13.846/2019 (BRASIL, 2019). O novo ordenamento legal, de forma bastante seletiva, estabelece critérios legais para a concessão do benefício previdenciário de auxílio-reclusão que, a despeito de não ter sido extinto tal instituto, restringe-o praticamente a tal ponto, assim como abordaremos na sequência.

\section{A Medida Provisória n. 871/2019 e sua conversão na Lei 13.846/2019: os efeitos restritivos}

A Medida Provisória n. 871, de 18 de janeiro de 2019, foi publicada pelo governo do presidente Bolsonaro com o objetivo de instituir os programas especiais para análise e revisão de benefícios previdenciários com indícios de irregularidade, assim como dos benefícios por incapacidade concedidos no regime geral de previdência social. A exposição de motivos coloca como justificativa da medida, a necessidade de promover melhorias na gestão dos benefícios por meio do combate a fraudes e apuração de benefícios com suspeita de irregularidades visando alcançar "[...] efeitos fiscais relevantes, com a potencial cessação de benefícios irregulares e fraudulentos e a recuperação dos valores indevidamente pagos." (BRASIL, 2019)

Com efeito, denota-se que os motivos que fundamentam a implantação deste programa de análise e revisão dos benefícios previdenciários estão nitidamente amparados na lógica de ajuste estrutura ${ }^{10}$, pro-

\footnotetext{
$\overline{{ }^{10} \text { Segundo Soares (2000) }}$ este modelo de ajuste estrutural é desencadeado por políticas liberalizantes para abertura comercial e financeira do país; privatizantes do setor público para comprimir a presença estatal e de desregulamentação dos mercados.
}

posta pelo ideário neoliberal do qual o governo federal de Bolsonaro encontra-se filiado. O propósito evidente destas medidas de ajuste fiscal é a desconstrução dos direitos sociais, considerados como custos ou gastos sociais que devem ser reduzidos ou eliminados em prol de assegurar a eficácia econômica e a liberdade de circulação do capital.

Ainda no bojo da exposição de motivos da Medida Provisória n. 871/2019, após destacar o impacto crescente do número de benefícios previdenciários concedidos por ordem judicial - e auxílio-reclusão é um deles -, ou seja, cerca de $15 \%$ do total de benefícios previdenciários pagos pelo INSS em 2018, propõe-se, de forma expressa, a restrição na concessão do benefício de auxílio-reclusão (BRASIL, 2019).

De modo que o artigo 80 e parágrafos da Lei n. 8.213/91 (BRASIL, 1991), com a redação alterada pela Lei 13.846/2019, resultado da conversão da Medida Provisória n. 871/2019 (BRASIL, 2019), passa a disciplinar a concessão do auxílio-reclusão mediante o preenchimento dos seguintes critérios:

Art. 80. O auxílio-reclusão será devido nas condições da pensão por morte, respeitado o tempo mínimo de carência estabelecido no inciso IV do caput do art. 25, aos dependentes do segurado de baixa renda recolhido à prisão em regime fechado, que não receber remuneração da empresa nem estiver em gozo de auxílio-doença, pensão por morte, salário-maternidade, aposentadoria ou abono de permanência em serviço.

(...)

$\S 3^{\circ}$ Para fins do disposto nesta Lei, considera-se segurado de baixa renda aquele que, no mês de competência de recolhimento à prisão, tenha renda, apurada nos termos do disposto no $\S 4^{\circ}$ deste artigo, de valor igual ou inferior àquela prevista no art. $13 \mathrm{da}$ Emenda Constitucional $n^{\circ} 20$, de 15 de dezembro de 1998, corrigido pelos índices de reajuste aplicados aos benefícios do RGPS.

$\S 4^{\circ} \mathrm{A}$ aferição da renda mensal bruta para enquadramento do segurado como de baixa renda ocorrerá pela média dos salários de contribuição apurados no período de 12 (doze) meses anteriores ao mês do recolhimento à prisão.

São significativas as mudanças legislativas no instituto do auxílio-reclusão. 
Primeiro, a norma passa a exigir a comprovação de tempo de carência de 24 contribuições mensais anteriores a data da prisão do segurado. Nos termos do artigo 24 da Lei n. 8.213/91 (BRASIL, 1991), o período de carência é definido como número mínimo de contribuições mensais indispensáveis para que o beneficiário faça jus ao benefício, considerada a data do efetivo recolhimento da primeira contribuição sem $\operatorname{atraso}^{11}$.

Trata-se de critério legal de acesso bastante restritivo que já tinha sido alvo de tentativa de implementação em 2014, com a publicação da Medida Provisória n. 664 que foi rejeitada pelo Poder Legislativo, mantendo a redação original do artigo 80 da Lei n. 8.213/91 (BRASIL, 1991) que não exigia tempo de carência.

É possível observarmos, com suporte a análise de Pochmann (2019, p. 249) acerca do que se considera a mais grave recessão econômica vivida no país desde a década de 1930 e diante do projeto neoliberal de "desmonte do padrão corporativo das relações de trabalho", que os reflexos no mundo do trabalho têm sido o desemprego em massa, o declínio dos postos formais de trabalho e a precarização das relações de trabalho. Certamente tal quadro político e econômico afetará a capacidade do cidadão de comprovar o prévio recolhimento de contribuição previdenciária, pelo período de 24 meses, para que sua família possa acessar o benefício previdenciário.

E a exposição de motivos da Medida Provisória n. 871/2019, no item 23, não deixa margem de dúvidas quanto a intencionalidade da exigência de carência prévia, quando afirma que tal critério obstará “[...] a concessão para pessoas fora do perfil que estejam desempregadas na véspera da prisão" (BRASIL, 2019).

O artigo 27-A da Lei 8.213/1991 (com a redação dada pela Lei 13.846/2019) ainda estabelece que na hipótese de perda da qualidade de segurado, para que seja possível a concessão do benefício de auxílio-reclusão, será necessário que o segurado retorne a contribuir pelo prazo mínimo de 12 contribuições mensais, a partir da data da nova filiação ao regime de previdência social para que possa acessar o benefício do auxílio-reclusão.

\footnotetext{
${ }^{11}$ Não se admite para efeitos de carência as contribuições recolhidas com atraso referentes a competências anteriores a data do primeiro recolhimento sem atraso.
}

A nova legislação também disciplina o critério de baixa renda na redação do caput do artigo 80 que disciplina a concessão do benefício de auxílio-reclusão. Em outras palavras, traz para o corpo da norma principal o critério seletivo que havia sido fixado na redação do artigo 13 da Emenda Constitucional n. 20/1998 (BRASIL, 1998).

Ainda, no que diz respeito a renda do segurado para fins de enquadramento do critério de baixa renda, institui-se o cálculo da média dos últimos salários de contribuição do segurado preso, apurados no período de doze meses anteriores ao mês do recolhimento à prisão.

Certamente, tal regramento visa restringir as concessões judiciais do auxílio-reclusão que caminhavam no sentido de considerar a ausência de renda do segurado preso na hipótese de desemprego ou de flexibilização do teto para fins de fixação do critério de baixa renda com a exclusão de parcelas eventuais ou não habituais no último salário de contribuição do segurado.

Esta sistemática de apuração da renda mensal do segurado vai de encontro ao entendimento firmado na jurisprudência dos Juizados Especiais Federais de considerar o último salário de contribuição no caso de segurado empregado ou a ausência de renda no caso de segurado desempregado, ainda que este auferisse renda superior ao teto fixado pelo INSS quando do vínculo empregatício, porque se levava em conta o valor da renda ou ausência da mesma na data da prisão.

Outro requisito imposto, de caráter igualmente restritivo, é a vedação de que o segurado esteja recebendo pensão por morte ou salário-maternidade. Vale lembrar que na redação original do artigo 80 da Lei n. 8.213 (BRASIL, 1991), havia a proibição de que o segurado preso estivesse recebendo remuneração da empresa ou no gozo de auxílio-doença, aposentadoria ou de abono de permanência em serviço.

Por ora, foram acrescidos outros dois benefícios previdenciários como impeditivos para o recebimento do auxílio-reclusão, lembrando que ambos têm periodicidade limitada no tempo: a pensão por morte tem duração máxima de 3 a 20 anos para faixa etária dos dependentes na data do óbito de menor de 21 anos a 43 anos. Para os dependentes a partir de 44 anos o período é vitalício. Já o salário-maternidade tem prazo de 120 dias. Estando o segurado percebendo um destes benefícios (auxílio-doença, abono 
de permanência, auxílio-maternidade, aposentadoria ou pensão por morte), no momento do cumprimento da pena no regime fechado, os seus dependentes não poderão acessar o auxílio-reclusão.

E, por fim, a nova legislação fixa como evento determinante do auxílio-reclusão apenas na hipótese do segurado ser recolhido à prisão em regime fechado, excluindo, deste modo, o regime semiaberto. É importante lembrar que no cumprimento da pena privativa de liberdade, o acusado que teve a pena privativa de liberdade fixada em limite superior a oito anos, inicia o seu cumprimento em regime fechado que, gradativamente, progride $^{12}$ para o regime semiaberto, como medida de retorno do preso ao convívio em sociedade. Assim, quando desta condição, a família do segurado recluso perderá a proteção previdenciária do auxílio-reclusão.

De modo que, em síntese, o Quadro 1 traz o registro comparativo das mudanças promovidas no instituto do auxílio-reclusão com a publicação da Lei 13.846/20199, resultado da conversão da Medida Provisória n. 871/2019.

Quadro 1: Mudanças no benefício do auxílio-reclusão promovidas pela Lei n. 13.846/2019

\begin{tabular}{|c|c|c|}
\hline $\begin{array}{l}\text { Requisitos para concessão do } \\
\text { auxílio-reclusão }\end{array}$ & Antes da publicação da Lei n. 13.846/2019 & Após a publicação da Lei n. 13.846/2019 \\
\hline Evento & Segurado preso em regime fechado ou semiaberto & Segurado preso em regime fechado \\
\hline $\begin{array}{l}\text { Hipóteses de vedação ao } \\
\text { recebimento }\end{array}$ & $\begin{array}{l}\text { Segurado preso não pode estar recebendo } \\
\text { remuneração da empresa, auxílio-doença, } \\
\text { aposentadoria ou de abono de permanência em } \\
\text { serviço. }\end{array}$ & $\begin{array}{l}\text { Acrescida as hipóteses de pensão por morte e } \\
\text { salário-maternidade. }\end{array}$ \\
\hline Beneficiários & $\begin{array}{l}\text { Dependentes previstos no rol do artigo } 16 \text { da Lei n. } \\
8.213 / 1991\end{array}$ & Mantido \\
\hline Carência & Não existia & $\begin{array}{l}24 \text { contribuições mensais anteriores a data da } \\
\text { prisão do segurado }\end{array}$ \\
\hline $\begin{array}{l}\text { Nova filiação após perda da } \\
\text { qualidade de segurado }\end{array}$ & Independia de prévio recolhimento & $\begin{array}{l}12 \text { contribuições mensais a partir da data da } \\
\text { nova filiação }\end{array}$ \\
\hline $\begin{array}{l}\text { Teto econômico para } \\
\text { enquadramento do conceito de } \\
\text { baixa renda }\end{array}$ & Reajustado anualmente por portaria ministerial. & Mantido \\
\hline $\begin{array}{l}\text { Renda mensal para apuração } \\
\text { do critério econômico de baixa } \\
\text { renda }\end{array}$ & $\begin{array}{l}\text { Salário de contribuição do segurado preso na data do } \\
\text { recolhimento à prisão. } \\
\text { Pode ser igual a zero em caso de situação de } \\
\text { desemprego comprovada. }\end{array}$ & $\begin{array}{l}\text { Média dos últimos salários de contribuição } \\
\text { do segurado preso, apurados no período } \\
\text { de doze meses anteriores ao mês do } \\
\text { recolhimento à prisão }\end{array}$ \\
\hline $\begin{array}{l}\text { Comprovação da condição de } \\
\text { segurado preso }\end{array}$ & $\begin{array}{l}\text { Para a concessão: certidão judicial que ateste o } \\
\text { recolhimento efetivo à prisão; } \\
\text { Para manutenção: prova de permanência na condição } \\
\text { de presidiário }\end{array}$ & Mantido \\
\hline
\end{tabular}

Fonte: Lei n. 8.213/1991 e MP 871/2019. Elaboração: a autora.

Com efeito, a mudança legislativa no instituto do auxílio-reclusão, com a inclusão de critérios seletivos têm o condão de restringir, drasticamente, o acesso ao benefício previdenciário e, desse modo, contribuir para o agravamento do quadro de pobreza do trabalhador e aumento dos níveis de desigualdade social já dimensionados por autores como Pochmann (2019) e Salomão, Raiher e Schimanski (2017). Isto porque o auxílio-reclusão foi criado com o objetivo de amparar a família do segurado preso, por meio da substituição temporária da fonte de subsistência dos membros da família que são submetidos aos efeitos sociais e econômicos decorrentes do encarceramento, em regime fechado, do segurado preso.

A alteração legislativa no instituto do auxílio-reclusão, assim como as recentes reformas trabalhista e previdenciária, além do novo pacto fiscal instituído com a Emenda Constitucional n. 95/2016, estão inseridos num projeto político de viés neoliberal, na

\footnotetext{
${ }^{12}$ A Lei de Execução Penal assegura a progressão do regime fechado de cumprimento da pena para o regime semi-aberto, com autorização para trabalho externo durante o dia e dever de passar a noite na prisão, após o cumprimento de pelo menos $1 / 6$ da pena e apresentar bom comportamento. Para os casos de crimes hediondos a progressão do regime se dá após o cumprimento de $2 / 5$ da pena privativa de liberdade, se for réu primário, e de $3 / 5$ da pena se for réu reincidente.
} 
sua versão mais recrudescedora já vivida no país, que propaga a ideia de priorização máxima da política econômica em detrimento da política social tida como fonte de desestabilização do equilíbrio fiscal do país. No plano ideológico coloca-se, então, como única alternativa possível para o Estado mínimo, a via do corte dos "gastos" com as políticas públicas que visam assegurar os direitos sociais previstos na Constituição Federal de 1988.

Por fim, é importante mencionar que a despeito da justificativa apresentada na exposição de motivos da Medida Provisória n. 871/2019 consistente no crescimento contínuo na concessão de benefícios previdenciários, por força da judicialização da matéria, o número de benefícios de auxílio-reclusão ativos no país representa menos de $10 \%$ do total de brasileiros presos nos regimes fechado e semiaberto.

Isto porque segundo dados do Banco Nacional de Monitoramento de Prisões do Conselho Nacional de Justiça ${ }^{13}$, no ano de 2017, existiam 296 mil pessoas condenadas em regime fechado e outros 105 mil brasileiros cumprindo pena em regime semiaberto. E, paralelamente, segundo dados divulgados no Anuário Estatístico da Previdência Social (BRASIL, Previdência Social, 2017) foram concedidos 22.605 benefícios de auxílio-reclusão, no mesmo ano.

Ainda vale observar que o número de auxílios-reclusão concedidos no país, segundo as informações divulgadas nos Anuários Estatísticos da Previdência Social (2013 a 2017), não sofreram significativos acréscimos, tendo sido inclusive registrado queda no número de benefícios concedidos, na linha histórica, a despeito do contínuo aumento no número de encarceramentos ${ }^{14}$ no Brasil. Assim é que em 2014 foram concedidos 24.074 auxílios-reclusão; em 2015 o número de benefícios caiu para 19.851; em 2016 foram 23.960 e, como dito anteriormente, em 2017 foram 24.074 auxílios-reclusão.

O que está a demonstrar que as alterações legislativas promovidas no instituto do auxílio-reclusão

\footnotetext{
${ }^{13}$ Informação disponível em:<http://www.cnj.jus.br/noticias/cnj/87316-bnmp-2-0-revela-o-perfil-da-populacao-carceraria-brasileira $>$. E também em: <https://www.flickr.com/photos/cnj_oficial/43110078254/in/photostream/>. Acesso em 2 de abr. de 2019.

${ }^{14} \mathrm{Na}$ atualidade, o Brasil tem a terceira maior população carcerária. Segundo dados do Banco de Monitoramento de Prisão do Conselho Nacional de Justiça em 2014 eram 622.202 presos; em 2016 eram 726.712 presos e até julho de 2019 eram 812.564 presos (CNJ. Banco de Monitoramento de Prisão. Disponível em: < http://www.cnj.jus.br/sistema-carcerario-e-execucao-penal >. Acesso em 20 de set. de 2019.
}

estão filiadas ao projeto político-ideológico de "contrarreforma conservadora” (FAGNANI, 1996, p. 86), com o redimensionamento do papel do Estado na execução das políticas sociais e a submissão das mesmas ao modelo de ajuste fiscal que propõe a focalização das políticas sociais em detrimento do caráter universal dos direitos sociais.

\section{CONSIDERAÇÕES FINAIS}

A publicação da Lei n. 13.846/2019, resultado da conversão da Medida Provisória n. 871/2019, tem o condão de limitar, de forma absolutamente drástica, os níveis de proteção social assegurados à família do segurado preso. A análise dos novos requisitos legais para a concessão do auxílio-reclusão nos permite apreender que a hermenêutica avançada do Poder Judiciário que buscou ampliar a proteção e a cidadania social no que diz respeito à concessão do auxílio-reclusão, aliada a uma visão distorcida e preconceituosa deste instituto por parte de membros da sociedade, serviram de pano de fundo para a mais nova investida do atual governo, de caráter conservador e filiado ao aparato teórico neoliberal, contra um direito social existente no país há mais de oito décadas.

Os critérios seletivos, previstos na Medida Provisória n. 871/2019, posteriormente convertida na Lei 13.846/2019, em especial a exigência de carência mínima de 24 contribuições e a restrição do evento determinante do benefício para os casos de cumprimento de pena em regime fechado, têm o condão de acarretar desproteção social, de forma imediata, a inúmeras famílias de segurados presos e de baixa renda, que estarão impossibilitadas de acessar o benefício previdenciário que assegura a substituição da renda do trabalhador que se encontra em cumprimento de pena.

O fato de o benefício do auxílio-reclusão estar vinculado ao sustento da família do preso, a restrição ao seu acesso que se impõe com as novas alterações legislativas resultará numa dupla vitimização às famílias que além de sofrer os efeitos sociais e familiares da reclusão de um membro do grupo familiar, ainda serão atingidas pelas consequências cotidianas da ausência de renda para a provisão dos membros daquele grupo familiar.

Não há dúvidas de que vivemos momentos funestos de ataques regressivos aos direitos sociais. No 
caso do auxílio-reclusão, ainda que não extinto expressamente tal direito social, a nova regulamentação estabeleceu critérios tão seletivos que certamente afetarão restritivamente este direito social. De modo que nos imperioso o debate crítico para o enfrentamento deste movimento de "contrarreforma conservadora" que visa, sobretudo, o desmonte dos direitos sociais.

\section{REFERÊNCIAS}

BRASIL. Constituição da República Federativa do Brasil de 1988. Disponível em: <

http://www.planalto.gov.br/ccivil_03/Constituicao/ Constituicao.htm>. Acesso em 2 de abr. de 2019.

BRASIL. Decreto n. 3.048, de 06 de maio de 1999. Aprova o regulamento da Previdência Social e dá outras providências. Disponível em: $<$ http://www.planalto.gov.br/ccivil_03/ decreto/D3048.htm>. Acesso em 2 abr. de 2019.

BRASIL. Emenda Constitucional n. 20, de 15 de dezembro de 1998. Modifica o sistema de previdência social, estabelece normas de transição e dá outras providências. Disponível em: <http://www.planalto.gov.br/ccivil_03/Constituicao/ Emendas/Emc/emc20.htm>. Acesso em 2 abr. de 2019.

BRASIL. Lei no 3.807, de 26 de agosto de 1960. Dispõe sobre a Lei Orgânica da Previdência Social. Disponível em: < https:/www2.camara.leg.br/legin/fed/lei/1960-1969/ lei-3807-26-agosto-1960-354492-publicacaooriginal-1-pl. html>. Acesso em 24 set. de 2019.

BRASIL. Lei n. 8.213, de 24 de julho de 1991. Dispõe sobre os Planos de Benefícios da Previdência Social e dá outras providências. Disponível em: <http://www.planalto.gov.br/ ccivil_03/LEIS/L8213cons.htm>. Acesso em 2 abr. de 2019.

BRASIL. Lei n. 10.666, de 8 de maio de 2003. Dispõe sobre a concessão da aposentadoria especial ao cooperado de cooperativa de trabalho ou de produção e dá outras providências. Disponível em: <http://www.planalto.gov. br/ccivil_03/leis/2003/L10.666.htm>. Acesso em 2 abr. de 2019.

BRASIL. Medida Provisória n. 664, de 30 de dezembro de 2014. Altera as Leis no 8.213 , de 24 de julho de $1991, \mathrm{n}^{\circ}$ 10.876, de 2 junho de 2004, $\mathrm{n}^{\circ} 8.112$, de 11 de dezembro de 1990, e a Lei $\mathrm{n}^{\circ} 10.666$, de 8 de maio de 2003. Disponível em: <http://www.planalto.gov.br/ccivil_03/_Ato20112014/2014/Mpv/mpv664.htm>. Acesso em 2 abr. de 2019.

BRASIL. Medida Provisória n. 871, de 18 de janeiro de 2019. Institui o Programa Especial para Análise de Benefícios com Indícios de Irregularidade, o Programa de Revisão de Benefícios por Incapacidade, o Bônus de Desempenho Institucional por Análise de Benefícios com Indícios de Irregularidade do Monitoramento Operacional de Benefícios e o Bônus de Desempenho Institucional por Perícia Médica em Benefícios por Incapacidade e dá outras providências. Disponível em: <http://www.planalto.gov.br/ ccivil_03/_Ato2019-2022/2019/Mpv/mpv871.htm>. Acesso em 2 abr. de 2019.

BRASIL. Ministério da Economia. Portaria n. 9, de 15 de janeiro de 2019. Dispõe sobre o reajuste dos benefícios pagos pelo Instituto Nacional do Seguro Social - INSS e dos demais valores constantes do Regulamento da Previdência Social - RPS. Disponível em: <http://pesquisa.in.gov.br/ imprensa/jsp/visualiza/index.jsp?data $=16 / 01 / 2019 \&$ jornal $=$ 515 \&pagina $=25>$. Acesso em 3 de abr. de 2019.

BRASIL. Previdência Social. Anuário Estatístico da Previdência Social. Ano 2015. Disponível em: <http:// sa.previdencia.gov.br/site/2019/03/AEPS-2017-13-03-19.1.pdf $>$. Acesso em 4 de abr. de 2019.

BRASIL. Previdência Social. Anuário Estatístico da Previdência Social. Ano 2017. Disponível em: <http:// sa.previdencia.gov.br/site/2019/03/AEPS-2017-13-03-19.1.pdf $>$. Acesso em 4 de abr. de 2019.

BRIGUET, M. R. C.; VICTORINO, M. C. L.; HORVATH JUNIOR, M. Previdência Social: aspectos práticos e doutrinários dos regimes jurídicos próprios. São Paulo: Atlas, 2007.

CHIES, L. A. B.; PASSOS, R. A. Auxílio-reclusão: a bizarra transmutação de um direito social e sua colonização perversa por um populismo punitivo. Textos \& Contextos (Porto Alegre), v. 11, n. 2, p. 273 - 291, ago./dez. 2012.

COSTA, L. C. da. A Previdência Social no Brasil num contexto de ajustes neoliberais. In: COSTA, L. C. da; DEL VALLE, A. H. (org.). A Seguridade Social no Brasil e na Argentina: os direitos sociais em tempos de ajustes neoliberais. Guarapuava: Unicentro, 2017, p. 155-184.

COIMBRA, J. R. Feijó. Direito previdenciário brasileiro. 7. ed., Rio de Janeiro: Edições Trabalhistas, 1997.

FAGNANI, E. Política social e pactos conservadores no Brasil: 1964-92. Cadernos Fundap, n. 21, 1996.

FALEIROS, Vicente de Paula. A questão da reforma da Previdência Social no Brasil. SER Social, Brasília, n. 7, mar. 2010.

FRIEDMAN, M. Capitalismo e liberdade. São Paulo: Nova Cultural, 1985.

KERSTENETZKY, C. L. O estado do bem-estar social na idade da razão: a reinvenção do estado social no mundo contemporâneo. Rio de Janeiro: Elsevier, 2012.

MARTINEZ, W. N. Reforma da previdência social: comentários à Emenda Constitucional n. 20/98. São Paulo: LTr, 1999.

MARTINS, S. P. Direito da seguridade social. 11ed. São Paulo: Atlas, 1999. 
NEVES, Marcelo. A constitucionalização simbólica. 3. ed. São Paulo: WMF Martins Fontes, 2011.

POCHMANN, M. Mundo do trabalho e organização dos trabalhadores. In: POCHMANN, M.; AZEVEDO, J. S. G. de. (org.) Brasil: incertezas e submissão? São Paulo: Fundação Perseu Abramo, 2019.

ROCHA, D. M. da. Comentários à Lei de Benefícios da Previdência Social. 9a . ed. revista e atualizada, Porto Alegre: Livraria do Advogado, 2009.

RUSSOMANO, M. V. Comentários à Consolidação das Leis da Previdência Social. Ed. São Paulo: Revista dos Tribunais, 1981.

SALOMÃO, I. C.; RAIHER, A. P.; SCHIMANSKI, E. Desenvolvimento e políticas públicas de proteção social: o caso brasileiro. In: COSTA, L. C. da; DEL VALLE, A. H. (org.). A Seguridade Social no Brasil e na Argentina: os direitos sociais em tempos de ajustes neoliberais. Guarapuava: Unicentro, 2017, p. 97-124.

SILVA. R. R. da. A Seguridade Social em disputa no Brasil. In: Políticas Sociais: padrões, tendências e desafios. Rio de Janeiro: Revista Praia Vermelha: estudos de política e teoria social. Vol. 28, n. 1, 2018.

SOARES, L. T. Os custos sociais do ajuste neoliberal na América Latina. São Paulo: Cortez. 2000. (Coleção Questões da Nossa Época, v. 78). 